\title{
IDENTIFICAÇÃO DE ÁREAS SUSCETÍVEIS A DESERTIFICAÇÃO DO ALTO SERTÃO SERGIPANO
}

\author{
Kaio César de Oliveira Tavares ${ }^{(a)}$, Alberto Santana da Cruz ${ }^{(b)}$, Daniel Rodrigues de Lira ${ }^{(\mathrm{c})}$, \\ Cristiano Aprígio dos Santos ${ }^{(\mathrm{d})}$.
}

\author{
${ }^{(a)}$ Departamento de Geografia Itabaina- Universidade Federal de Sergipe- UFS, E-mail: \\ kaiocesaroliveira@hotmail.com

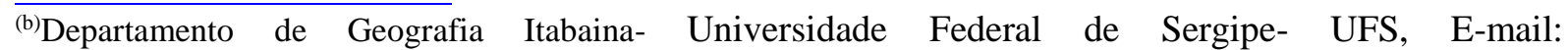 \\ alberto_santana113@hotmail.com \\ ${ }^{(c)}$ Departamento de Geografia Itabaina- Universidade Federal de Sergipe- UFS, E-mail:dniellira@gmail.com \\ (d) Departamento de Geografia Itabaina- Universidade Federal de Sergipe- UFS, E-mail: aprigeo@ gmail.com
}

\section{Eixo: GEOTECNOLOGIA E MODELAGEM AMBIENTAL EM GEOGRAFIA FÍSICA}

Resumo:

\begin{abstract}
O processo de apropriação da natureza pelo homem tem causado diversos problemas no contexto da biosfera. Dentre tais problemas tem-se a degradação dos solos no semiárido brasileiro, processo esse denominado como desertificação. A desertificação é definida oficialmente como, a degradação da terra nas zonas áridas, semiáridas e subúmidas secas, resultante de vários fatores, incluindo as variações climáticas e as atividades humanas.
\end{abstract}

\section{Palavras chave: Degradação do solo, Ação antrópica, Semiárido nordestino}

\section{Introdução:}

Entende-se por desertificação o processo de empobrecimento do solo até o ponto em que ele não pode mais garantir a subsistência da população de determinado local, ou seja, a perda total da fertilidade natural, processo este de causas naturais e antrópicas, a degradação das terras traz consigo consequências dramáticas e, em muitos casos, de difícil recuperação, gerando altíssimos custos sociais, econômicos e ambientais. No Brasil, as áreas suscetíveis a desertificação no Brasil abrange uma área de 1.340.000 $\mathrm{km}^{2}$ atingindo diretamente 30 milhões de pessoas. Desse total, 180 mil quilômetros quadrados já se encontram em processo grave e muito grave de desertificação, concentrados principalmente nos estados do Nordeste, que têm 55,25\% do seu território atingido em diferentes graus de deterioração ambiental.

Nascimento (2006) assevera que, em regiões semiáridas, como o Nordeste brasileiro (NEB), estes problemas são agravados por conta do seu quadro geoambiental vulnerável, onde, principalmente os cursos de água, solo e geobotânica, são consumidos e exauridos vorazmente, aumentando assim a susceptibilidade às contingências climáticas, sobretudo termo pluviométrico, como a desertificação. Segundo Roxo (2006) a desertificação ocorre, ou é passível de ocorrer nas diversas regiões de clima seco do mundo, principalmente em virtude de determinadas formas de manejo a que são submetidos os recursos naturais existentes, em particular a vegetação e os solos. 


\section{OS DESAFIOS DA GEOGRAFIA FÍSICA NA FRONTEIRA DO CONHECIMENTO \\ Instituto de Geociências - Unicamp \\ Campinas - SP \\ 28 de Junho à 02 de Julho de 2017}

Para Souza (2008), a retirada da vegetação é a ação mais comum que pode desencadear o processo de desertificação, e uma das consequências mais sérias está relacionada aos solos das regiões afetadas, em decorrência do aumento da erosão e os seus efeitos na fertilidade do solo. Portanto, a cobertura vegetal apresenta enorme importância para a diminuição do desenvolvimento da desertificação, uma vez que protege o solo da ação inicial dos processos erosivos. No mesmo sentido, a ausência da cobertura vegetal pode anunciar a susceptibilidade dos solos ao ataque dos agentes erosivos desencadeadores do processo da desertificação.

De acordo com Programa de Ação Nacional de Combate à Desertificação e Mitigação dos efeitos da Seca, o PAN BRASIL, as áreas susceptíveis a desertificação cobre uma superfície que abrange, um total de municípios nos noves Estados do Nordeste (entre eles Sergipe), além do norte de Minas Gerais e do norte do Espírito Santo (BRASIL, 2004).

O Estado de Sergipe segundo a UNCCD (1997) citado pela SEMARH (2010) é considerado área frágil com três zonas: 1)Uma estreita faixa litorânea sem riscos de desertificação; 2) Uma faixa central abrangendo todo o Estado de Norte a Sul, com riscos de ocorrência do processo de desertificação; 3) Uma faixa do sertão semiárida, com riscos elevados de desertificação. Neste terceiro ponto é onde se encontra nossa área de estudo, a Microrregião do Alto Sertão Sergipano.

O presente estudo visa, analisar as paisagens susceptíveis a desertificação utilizando-se dos produtos e técnicas de sensoriamento remoto e geoprocessamento.

\section{Material e Métodos:}

Para a realização do presente estudo foram utilizados múltiplos procedimentos metodológicos, a saber: revisão bibliográfica; pesquisa documental.

Para o Mapeamento foi utilizada imagem do sensor L8 OLI/ TIRS, de 24 julho de 2016, por meio do United States Geological Survey (USGS), Site 〈http://earthexplorer.usgs.gov/>. De ponto e orbita: 215/67. A escolha foi feita tomando como referência o período chuvoso e pouca cobertura de nuvens para facilitar a identificação dos alvos. Para o processamento dos dados deste trabalho, foi utilizado o pacote de software ArcGis, a partir da licença acadêmica free trial, onde foi possível realizar o cálculo do Normalized Difference Vegetation Index- NDVI, e obtido da razão entre a diferença das refletividades do infravermelho próximo e do vermelho.

Equação (1)

$$
\mathrm{NDVI}=(\mathbf{A}-\mathbf{B}) /(\mathbf{A}+\mathbf{B})(1) \text { Onde: }
$$

A é a reflectância no infravermelho próximo; B é a reflectância no vermelho. 


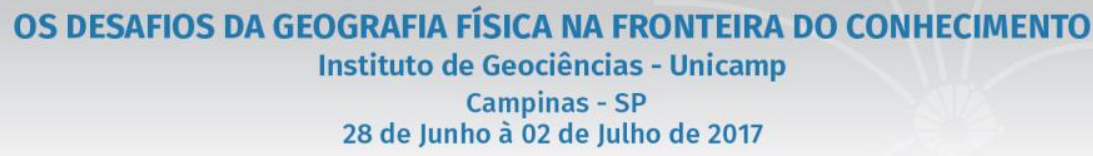

Para melhor visualização do resultado, o NDVI foi dividido em seis classes. Para classificação supervisionada foi utilizada a técnica de Máxima Verossimilhança (Maxver), método que considera a ponderação das distâncias entre medias dos níveis digitais das classes, utilizando parâmetros estatísticos, a qual dirão a probabilidade de um pixel pertencer ou não a uma determinada classe, levando em consideração a distribuição espectral da classe.

\section{Resultados e discussões:}

\section{1 Área de Estudo}

O território do Alto Sertão Sergipano, correspondente à Microrregião Sergipana do Sertão do São Francisco, formada pelos municípios de Canindé de São Francisco, Nossa Senhora da Glória, Poço Redondo, Monte Alegre de Sergipe, Nossa Senhora de Lourdes, Gararu e Porto da Folha. (Figura I)

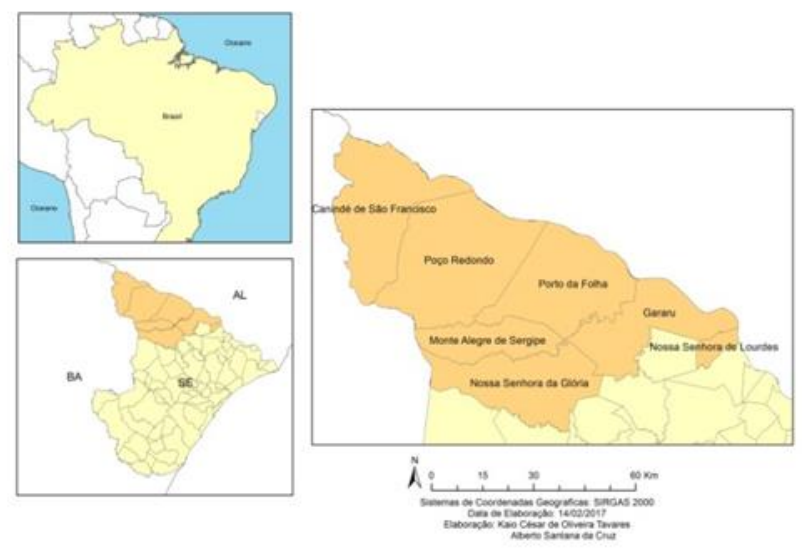

Figura I: Localização do Alto Sertão Sergipano

Região que de acordo com o Programa de Ação Nacional de Combate à Desertificação e Mitigação dos efeitos da Seca (PAN BRASIL), é área do estado mais afetada pelo processo de desertificação, sendo classificada de acordo com os indicadores adotados como Muito Grave. Portanto, tendo em vista a importância que possui a vegetação no combate à desertificação, e o nível avançado deste processo no Alto Sertão de Sergipe.

\section{Resultados}

Em Sergipe a desertificação vem se intensificando em decorrência de alguns fatores como sobre pastoreio, desmatamento indiscriminado e uso intenso dos recursos naturais da caatinga, em forma de extrativismo vegetal, de lenha, madeira em toras, e a enorme quantidade produzida de carvão vegetal (PAE-SE, 2011).

O desmatamento elevado no Bioma Caatinga vem gerando processos de desertificação em diversas áreas, alterando diretamente a biota, o microclima e os solos. As isoietas do sertão são em torno de 


\section{OS DESAFIOS DA GEOGRAFIA FÍSICA NA FRONTEIRA DO CONHECIMENTO \\ Instituto de Geociências - Unicamp \\ Campinas - SP \\ 28 de Junho à 02 de Julho de 2017}

$800 \mathrm{~mm}$ decaindo para $500 \mathrm{~mm}$ a oeste, entre os meses de fevereiro a Agosto a precipitação média foi de 102.3mm, bem abaixo do normal. Empilhamento das bandas 4-3-2, formando uma imagem RGB, na cor real (Figura II).

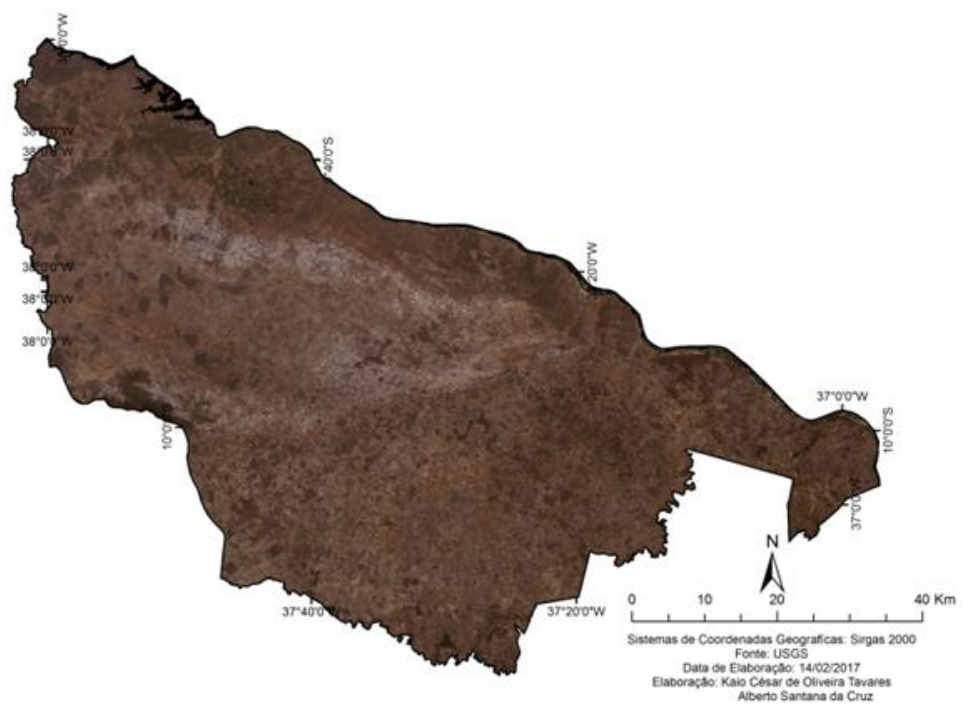

Figura II- Alto sertão cor natural 2016

A seguir podemos ver o mapa da Cobertura vegetativa do Alto Sertão Sergipano do ano 2016 (figura III), apresentando seis classes.

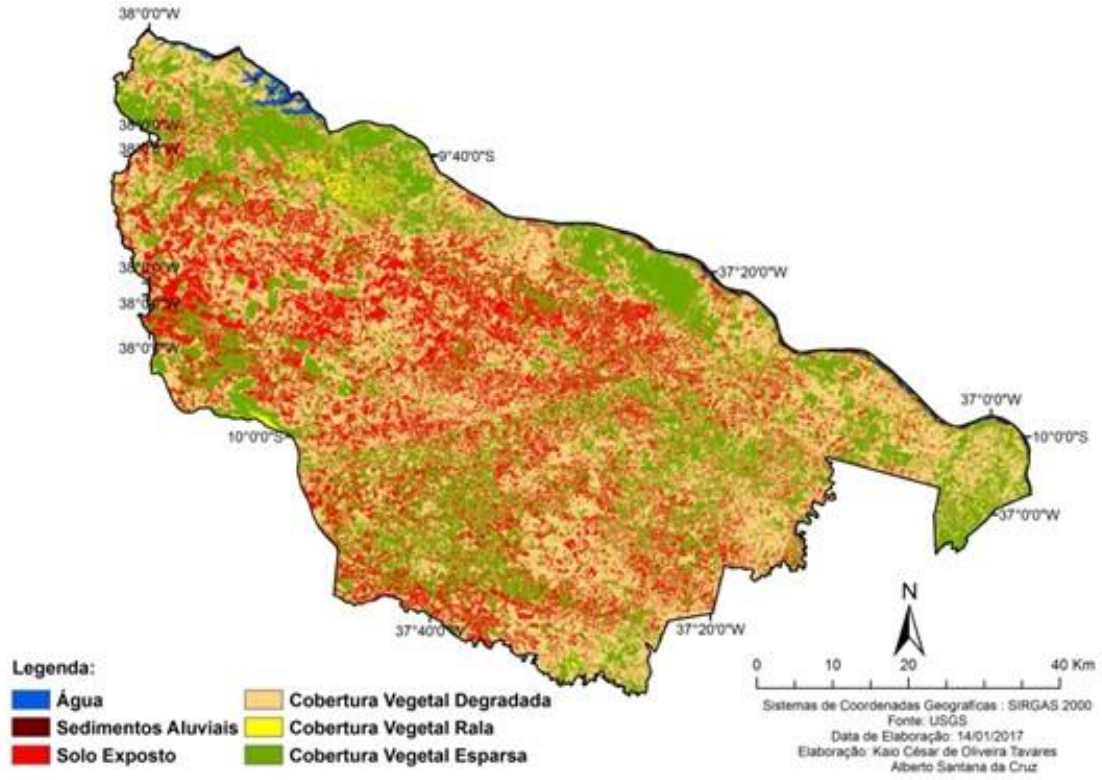

Figura III: Cobertura Vegetal do Alto Sertão Sergipano 2016

A escassez de chuvas de acordo com à Secretaria de Estado do Meio Ambiente e dos Recursos Hídricos (SEMARH) do estado de Sergipe. A explicação se dá ao resultado da influência da subsidência decorrente da célula de Walker e Hadley gerada pelo El Ninõ sobre partes dos setores do NEB (Nordeste do Brasil), Em especial, Sergipe e Alagoas, refletindo na anomalia de precipitação. 
No final do ano 2016, o fenômeno El Ninõ encontrava-se em declínio no pacífico Equatorial especialmente adjacente à costa da América do sul. Porém, ao longo desse período, o fenômeno apresentou importantes anomalias positivas de Temperatura da Superfície do Mar (TSM) na porção central e oeste do Pacífico Equatorial, que poderia influenciar a distribuição pluviométrica sobre o Brasil nos meses subsequentes. O resultado desse longo período de chuvas escassas e ação antrópica, corroboraram para um comportamento diferenciado na cobertura vegetal.

\section{Conclusões:}

O levantamento da vegetação nas áreas de Caatinga, foi desenvolvido como base no uso de técnicas de Sensoriamento Remoto e Geoprocessamento, as quais vêm fornecendo informações importantes. Técnicas estas que foram importantes nos estudos sobre desertificação, pois até certo ponto são capazes de gerar dados valiosos na análise desse tipo de degradação, sabendo que é indispensável um trabalho de campo, que além de importante acaba tornando-se necessário.

Existe uma forte relação entre a vegetação, os processos erosivos e as diferentes escalas. Nesse caso, na área degradada, a rarefação da vegetação favorece a ação das chuvas torrenciais típicas da região e consequentemente a lixiviação e a intensificação da destruição dos agregados do solo.

A influência direta do desmatamento na modificação da estrutura original dos solos afetados, os quais apresentarão aumento de densidade e redução da porosidade, compactação e formação de crostas nas camadas superficiais, aumento da resistência à penetração e a consequente diminuição da infiltração da água, o que leva a intensificação dos efeitos da seca, aspectos já detectados em outras áreas do semiárido brasileiro.

\section{Bibliografia}

BRASIL. Programa de Ação Nacional de Combate à Desertificação e Mitigação dos Efeitos da Seca/PANBrasil. Brasília (DF): Ministério do Meio Ambiente/Secretaria de Recursos Hídricos, 2004. 214p.

CCD. Convenção das Nações Unidas de Combate à Desertificação. Tradução: Delegação de Portugal. Lisboa (PT): Instituto de Promoção Ambiental, 1995. 55p.

EMBRAPA. Sistema brasileiro de classificação de solos. Rio de Janeiro (RJ): Embrapa/Centro nacional de Pesquisa de Solos, 2006. 306p.

NASCIMENTO, F. R. Degradação ambiental e desertificação no Nordeste Brasileiro: ocontexto da Bacia Hidrográfica do rio Acaraú - CE. (Tese de doutoramento em Geografia). UFF: RJ, 2006. 370p.

ROXO, M. J. O panorama mundial da desertificação. MOREIRA, E. (Org.). Agricultura familiar e Desertificação. João Pessoa: Ed. Universitária da UFPB, 2006.p. 11-32 